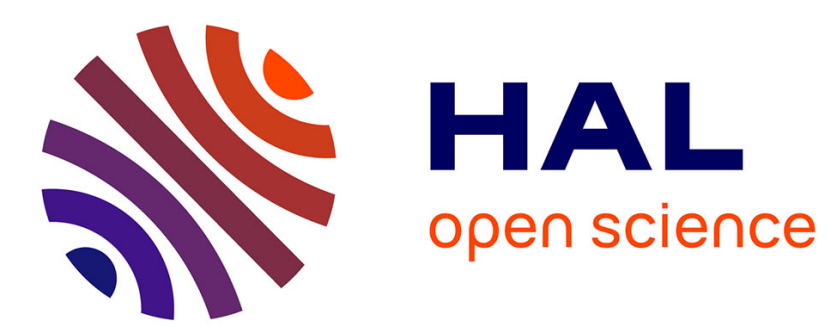

\title{
Experimental measurement of the nonlinearities of electrodynamic microphones
}

\author{
Romain Ravaud, Guy Lemarquand, Tangi Roussel
}

\section{To cite this version:}

Romain Ravaud, Guy Lemarquand, Tangi Roussel. Experimental measurement of the nonlinearities of electrodynamic microphones. Applied Acoustics, 2009, 70, pp.1194-1199. 10.1016/j.apacoust.2009.03.009 . hal-00390067

\section{HAL Id: hal-00390067 https://hal.science/hal-00390067}

Submitted on 31 May 2009

HAL is a multi-disciplinary open access archive for the deposit and dissemination of scientific research documents, whether they are published or not. The documents may come from teaching and research institutions in France or abroad, or from public or private research centers.
L'archive ouverte pluridisciplinaire HAL, est destinée au dépôt et à la diffusion de documents scientifiques de niveau recherche, publiés ou non, émanant des établissements d'enseignement et de recherche français ou étrangers, des laboratoires publics ou privés. 


\title{
Experimental measurement of the
}

\section{nonlinearities of electrodynamic microphones}

\section{for reciprocal calibration}

\author{
R. Ravaud, G. Lemarquand* and T. Roussel \\ Laboratoire d'Acoustique de l'Universite du Maine, UMR CNRS 6613, Avenue \\ Olivier Messiaen, 72085 Le Mans Cedex 9, France
}

\begin{abstract}
This paper presents an experimental way of characterizing the nonlinearities of electrodynamic microphones used as acoustical sources. This functioning occurs for reciprocal calibration techniques. For this purpose, its electrical impedance is measured with a Wayne Kerr wedge which has an excellent precision. Moreover, it can be noted that the Thiele and Small model is used to characterize its electrical impedance. Furthermore, an experimental method based on Simplex algorithm allows us to construct polynomial laws which describe the dependence of the Thiele and Small parameters with the input voltage. The nonlinear variations obtained allow us to determine the nonlinear differential equation of the electrodynamic microphone. Then, this equation is solved numerically in order to confirm the accuracy of the polynomial laws obtained by the Simplex algorithm. The distortions are measured with a laser Doppler velocimeter and compared with the ones obtained by the numerical solving of the nonlinear differential equation. The experimental displacement spectrum is consistent with the theoretical one.
\end{abstract}

Key words: Microphone, Electrodynamic, Electrical Impedance 


\section{$1 \quad 1 \quad$ Introduction}

2 Electrodynamic microphones are generally used either for recording voice and 3 instruments or for reciprocal calibration techniques. They are often charac-

4 terized by their directivity (omnidirectional, cardiod, supercardiod, etc...).

5 Moreover, most of the microphones are designed as pressure microphones or 6 pressure gradient microphones which usually leads to sound coloration. Micro-

7 phone directivity is the most important property since it allows to select the 8 sound produced by only one instrument among other instruments. However, 9 it is not the only property which has to be taken into account. Microphone 10 linearity is an important characteristic which is strongly linked to sound fi11 delity.Distortions produced by electrodynamic microphone nonlinearities is a 12 scientific topic which is studied little. However, the most interesting studies on the microphone characterization were done by Abuelma'atti with various 14 technologies of microphones[1]-[3] and Niewiarowicz [4][5]. Experimentally, a 15 lot of parameters have to be taken into account and vary together according 16 to input level. For this reason, the accurate estimation of the electrodynamic microphone main nonlinearities is difficult. Moreover, time-varying effects are also present and can modify the recording quality by amplifying or reducing distortions. The knowledge of these nonlinearities can really help designing new microphones with improved sound quality.

\footnotetext{
* Corresponding author.
}

Email address: guy.lemarquand@univ-lemans.fr (G. Lemarquand). 
Acutally, new developments in microphones have been performed to respond to recent demands for miniaturization and high sound quality [6]-[10]. These new developments are based on the traditional technology. Moreover, the nonlinearities observed in these new microphones have the same physical origins as the nonlinearities observed in electrodynamic loudspeakers even if their functioning is different. Therefore, the studies carried out with electrodynamic loudspeakers [11]-[20] can be useful for the electrodynamic microphone ones. However, electrodynamic microphones are damping controlled whereas the electrodynamic loudspeakers are mainly designed to be mass controlled. Consequently, electrodynamic microphones have a poor transient response which is the most important defect. It can be noted that it is one of the main problems of electrodynamic microphones but this is not the only one. This paper presents an experimental way of characterizing the nonlinearities of electrodynamic microphones. This experimental method is based on a very accurate measurement of the electrical impedance of the electrodynamic microphone. We can say that that the electrical impedance measurement of such a transducer is the most accurate measurement we can generally realize in a laboratory. Moreover, such a measurement is simple to perform. Consequently, the experimental method presented in this paper allows us to guess what must change in an electrodynamic microphone in order to improve its fidelity. In addition, the electrodynamic microphone is used as an acoustical source in this paper. This allows us to use important input voltages to show the nonlinear effects of such transducers. Furthermore, it can be noted that the Thiele and Small model [21] is used to characterize the electrical impedance of the electrodynamic microphone. We will show that the Thiele and Small parameters depend on the input voltage and consequently, some distortions are created. Such distortions are measured with a laser Doppler velocimeter and predicted 
theoretically by solving numerically the nonlinear differential equation of the electrodynamic microphone. We can say that the experimental displacement spectrum is consistent with the theoretical spectrum. The first section presents the analytical classical model of an electrodynamic microphone and its limits.

The second section presents an experimental method based on the electrical impedance measurement to characterize the variations of the nonlinear parameters that describe the electrodynamic microphone. This way of characterizing a nonlinear system has been used in a previous paper for studying the electrodynamic loudspeaker nonlinearities[22]. The third section presents both the theoretical and the experimental spectrums.

\section{Classical model of electrodynamic microphones and its limits}

An electrodynamic microphone is a transducer which transforms acoustic signals into electrical signals. Such an electrodynamic transducer generally includes a magnet motor, a rim and a diaphragm. The diaphragm vibration due to the acoustical excitation (the voice for example) engenders the movement of a coil which moves between two yoke pieces. Moving coil microphones use the same dynamic principle as in a loudspeaker, only reversed. When sound enters through the windscreen of the microphone, the sound wave moves the diaphragm. When the diaphragm vibrates, the coil moves in the magnetic field, producing a varying current in the coil through electromagnetic induction. However, it must be emphasized here that the parameter values are extremely different between an electrodynamic microphone and an electrodynamic loudspeaker. The apparent internal resistance $R_{e}$ of an electrodynamic microphone can reach $800 \Omega$ whereas it varies approximately from $2 \Omega$ to $10 \Omega$ 
95

for an electrodynamic loudspeaker. Such a difference has a great influence on the dynamic of these two transducers. In addition, the equivalent damping parameter $R_{m s}$ is rather weak for electrodynamic microphones: we can also say that its variation with input voltage generates distortions that are less important than the other Thiele and Small parameters when an electrodynamic microphone is used as an acoustical source. In fact, we can say that $R_{m s}$ represents the measurement of the losses, or damping, in a driver's suspension and moving system. Consequently, as the voice-coil displacement is greater for electrodynamic loudspeakers, the losses are generally greater. This is why this parameter does not have the same influence on the acoustical response between electrodynamic microphones and electrodynamic loudspeakers. Furthermore, the eddy currents, commonly represented by $R_{\mu}$, do not appear at the same frequency between an electrodynamic microphone and an electrodynamic loudspeaker. The reason lies in the fact that the magnet dimensions and the magnetic circuit dimensions is smaller in electrodynamic microphones.

Two differential equations can be used to describe the electrodynamic microphone. Such equations are also used for modeling electrodynamic loudspeakers [23]-[25]. The first one is given by (1).

$$
u(t)=R_{e} i(t)+L_{e} \frac{d i(t)}{d t}+B l \frac{d x(t)}{d t}
$$

where $x(t)$ is the position of the coil, $l$ is the length of the coil, $L_{e}$ is the coil inductance, $i(t)$ is the coil current, $B l$ is the force factor, $R_{e}$ is the electric resistor of the coil and $u(t)$ is the input voltage. The second differential equation is given by Eq.(2).

$$
M_{m s} \frac{d^{2} x(t)}{d t^{2}}-B l i(t)=-k x(t)-R_{m s} \frac{d x(t)}{d t}
$$


where $M_{m s}$ is the mass of the diaphragm, $B l$ is the force factor, $k$ is the equivalent stiffness of the suspensions and $R_{m s}$ is the equivalent damping parameter. Inserting Eq.(1) in Eq.(2) leads to the complex electrical impedance given by given by Eq.(3).

$$
Z_{e}=R_{e}+j L_{e} w+\frac{B l^{2}}{R_{m s}+j M_{m s} w+\frac{k}{j w}}
$$

By taking into account the eddy currents which occur at high frequencies [26], Eq.(3) is expressed as follows (Eq.4):

$$
Z_{e}=R_{e}+\frac{j R_{\mu} L_{e} w}{j L_{e} w+R_{\mu}}+\frac{B l^{2}}{R_{m s}+j M_{m s} w+\frac{k}{j w}}
$$

All the parameters in Eq.(3) could be called the electrodynamic microphone parameters. As the parameters that describe the electrodynamic loudspeakers are the same, the parameters in Eq.(3) can also be called the Thiele and Small parameters. However, it must be emphasized that the parameter values are not comparable and thus, the acoustical response is very different. The main assumption of this classical model is that it is a linear model. In the next section, it is shown that a linear model is not sufficient for describing accurately the electrodynamic microphone behavior. Moreover, the nonlinearities are also different between electrodynamic loudspeakers and electrodynamic microphones. For example, the voice-coil excursion of an electrodynamic loudspeaker is important and generate important sound pressure levels compared to the ones produced by electrodynamic microphones used as acoustical sources. Consequently, the nonlinear effects that are often predominant at low frequencies for electrodynamic loudspeakers are different for electrodynamic microphones. 


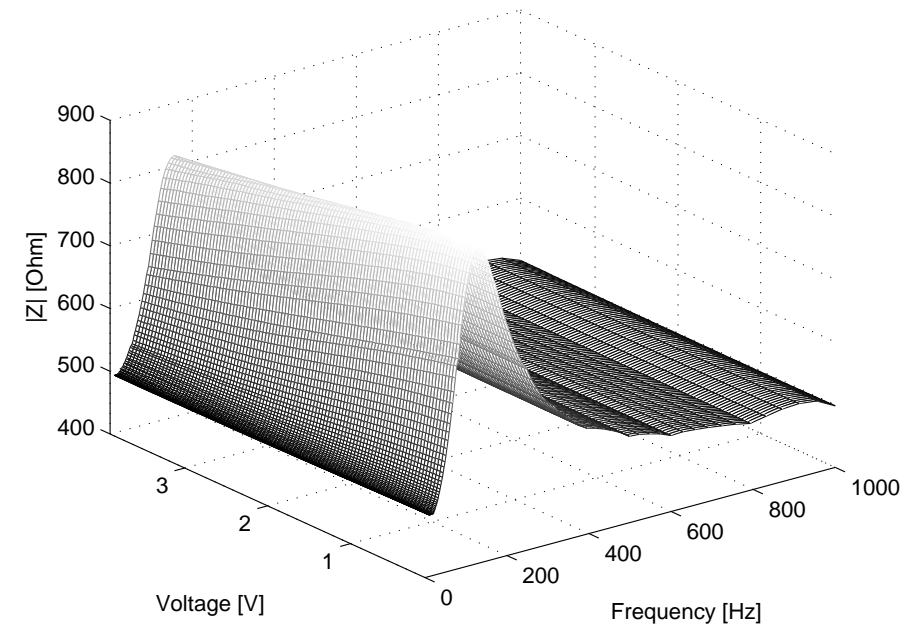

Fig. 1. Experimental three-dimensional representation of the electrical impedance magnitude of the electrodynamic microphone (voltage: $0 \mathrm{~V} ; 4 \mathrm{~V}$ )(frequency: 0 $\mathrm{Hz} ; 1000 \mathrm{~Hz})(|Z|: 400 \Omega ; 900 \Omega)$

\subsection{Limits of a linear electro-acoustical model}

This section presents the limits of the linear model for characterizing electrodynamic microphones. To do so, an electrodynamic microphone is placed in an anechoic chamber. An electrical impedance measurement is realized by using a Wayne Kerr wedge that has an excellent precision $\left(10^{-4} \Omega\right)$. A voltage measurement is carried out with levels varying from $100 \mathrm{mV}$ to $4 \mathrm{~V}$. During our experiment, the electrodynamic microphone is used as an acoustical source. Even though this situation is rather rare, the nonlinearities determined with such an approach represent very well the main defects in electrodynamic microphones. This is in fact the main aim of this paper: an accurate electrical impedance measurement can be used to estimate electrodynamic microphone nonlinearities. The electrical impedance magnitude is represented versus the input voltage and the frequency in Fig.(1) while its phase is represented in Fig. (2) A two-dimensional view allows us to see more precisely the nonlin- 


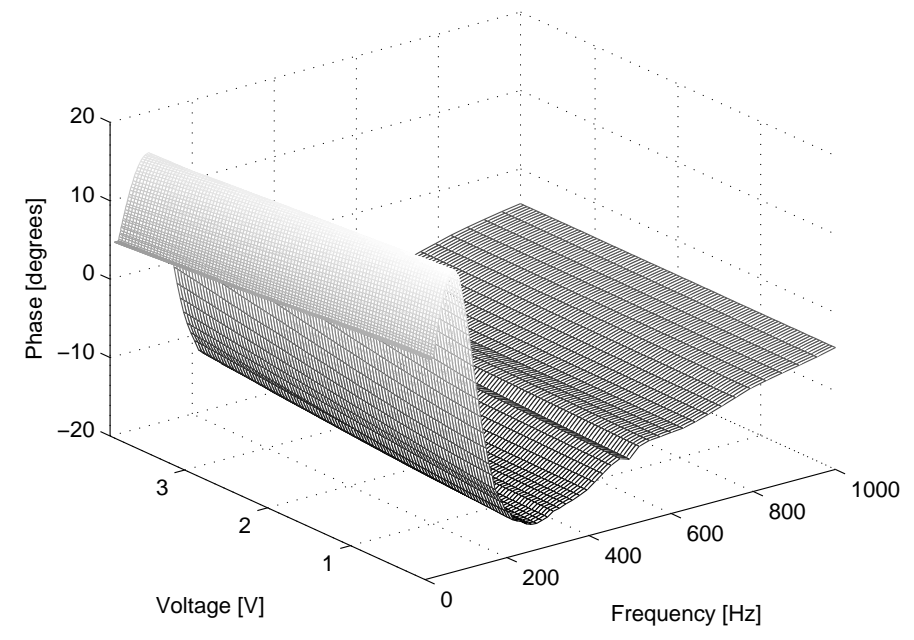

Fig. 2. Experimental three-dimensional representation of the electrical impedance phase of the electrodynamic microphone (voltage: $0 \mathrm{~V} ; 4 \mathrm{~V}$ )(frequency: $0 \mathrm{~Hz} ; 1000$ $\mathrm{Hz}$ )(phase: $-20 \operatorname{deg} ;+20 \operatorname{deg})$

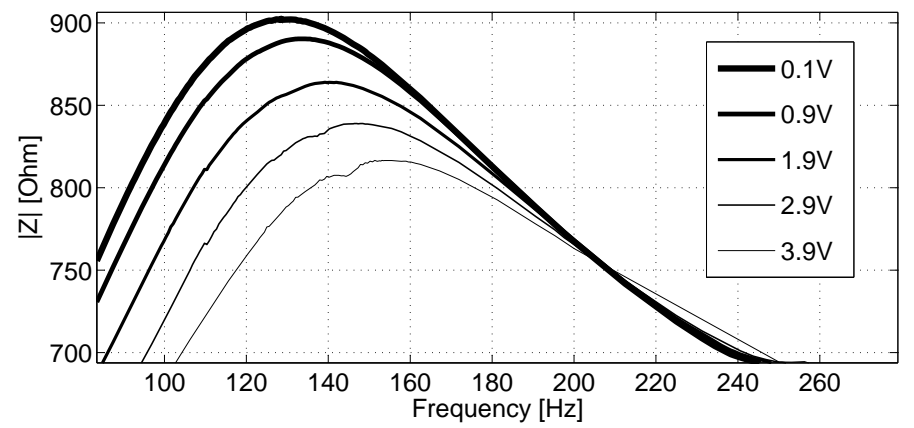

Fig. 3. Two-dimensional representation of the electrical impedance magnitude of the electrodynamic microphone (frequency: $100 \mathrm{~Hz} ; 260 \mathrm{~Hz})(|Z|: 700 \Omega ; 900 \Omega$ ) ear phenomena of the two previous representations (Figs. 3 and 4). Figures 3 and 4 shows that the electrical impedance of the electrodynamic microvaries with respect to the input voltage; this implies that the stiffness of the suspensions or the equivalent mass depend on input voltage. In conclusion, Eq.(4) which is generally used to describe the electrodynamic microphone is not sufficient to correctly describe its nonlinear effects. Strictly speaking, all 


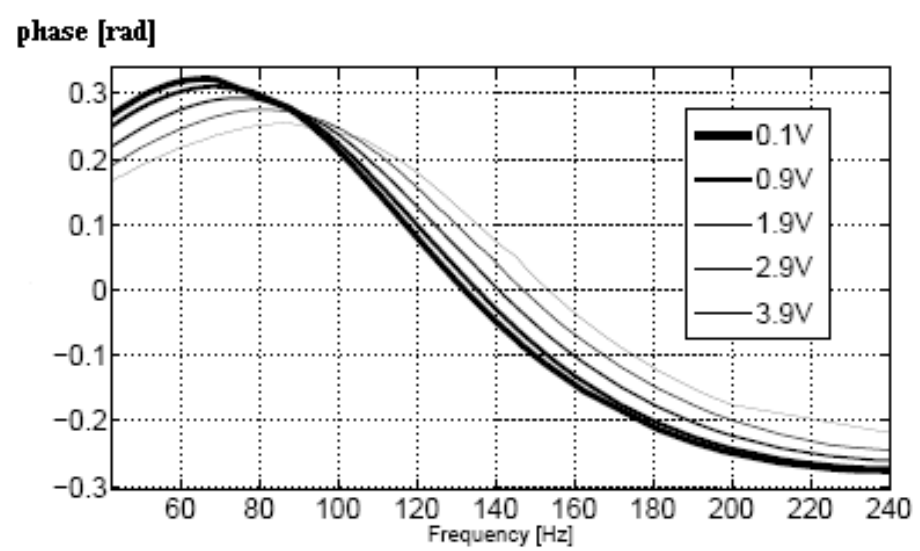

Fig. 4. Two-dimensional representation of the electrical impedance phase of the electrodynamic microphone (frequency: $60 \mathrm{~Hz} ; 240 \mathrm{~Hz}$ )(phase: $-0.3 \mathrm{rad} ;+0.3 \mathrm{rad}$ )

the parameters which define the electrical impedance (Eq.4) are a function of both input level and time. Obtaining the variation laws of these parameters is necessary in order to improve the design of electrodynamic microphones and predict the distortions created by themselves. As a consequence, a general method should be found in order to determine which parameters vary a lot with the input voltage and produce some distortions. Such a general experimental method is discussed in the next section.

\section{Experimental method to derive the nonlinear variations of the Thiele and Small parameters}

\subsection{Introduction}

Our experimental method to derive the dependence of the Thiele and Small parameters with the input voltage is based on the electrical impedance measurement of the electrodynamic microphone. A real-time algorithm has been put forward to measure this impedance with a Wayne Kerr wedge that has an 
Each Thiele and Small parameter is represented like the previous form. Consequently, the difference $\Delta Z_{e}$ is expressed as follows:

$$
\Delta Z=\sum_{n=0}^{n=2}\left\|Z^{(e x p)}(u)-Z^{(t h e o)}(u)\right\|^{2}
$$


where

$$
\begin{array}{r}
Z^{(\text {theo })}(u)=R_{e}(u)+\frac{j R_{\mu}(u) L_{e}(u) w}{j L_{e}(u) w+R_{\mu}(u)} \\
+\frac{B l(u)^{2}}{R_{m s}(u)+j M_{m s}(u) w+\frac{1}{j C_{m s}(u) w}}
\end{array}
$$

When the algorithm converges, all the values describing the nonlinear parameters obtained are used to solve numerically the nonlinear differential equation of the electrodynamic microphone. Figure 5 represents the error sheet between the experimental results and the theoretical ones when the Thiele and Small parameters are constant. The mean difference between the experimental and the theoretical values is $6.0 \Omega$. In this case, we did not take into account the nonlinear variations of the Thiele and Small parameters determined by the Simplex algorithm. Figure (6) represents the error sheet between the experimental resuts and the theoretical one when the variations of the Thiele and Small parameters are taken into account. The mean difference between the experimental and the theoretical values is $2.9 \Omega$. As a consequence, the improvement of the electrodynamic microphone model is only possible if the nonlinear variations of the Thiele and Small parameters are taken into account.

\subsection{Variations of the Thiele and Small parameters}

This section discusses the sensitivity of the Thiele and Small parameters to the least mean square method. To do so, we assume that only one parameter varies at a time (though the other Thiele and Small parameters are constant). By using our least square method based on the simplex method, we determine the difference of the impedance (magnitude and phase) between the model with constant parameters and the model with one varying parameter. This 


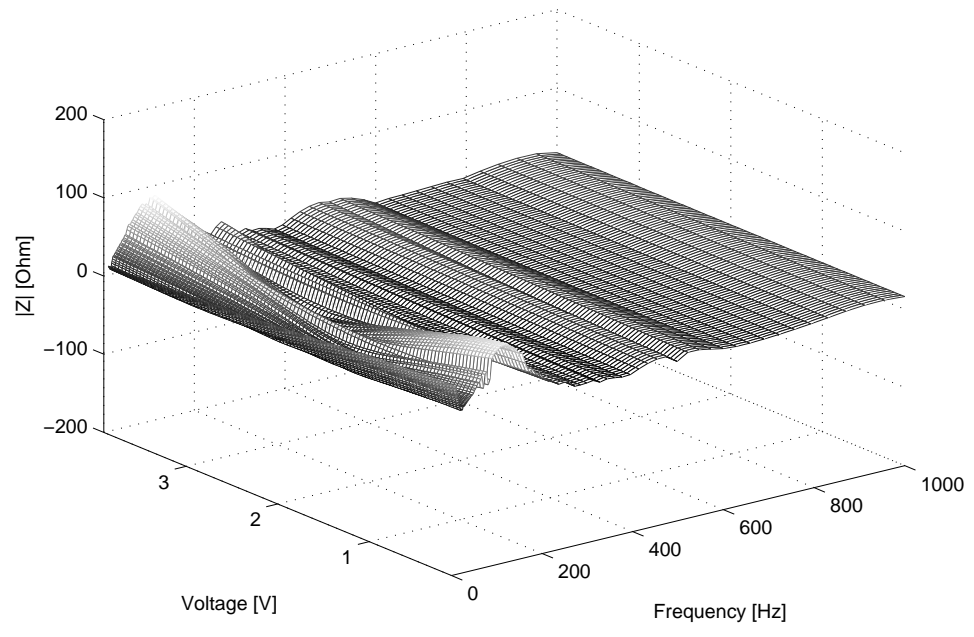

Fig. 5. Three-dimensional representation of the difference between the experimental impedance and the theoretical impedance ; the theoretical impedance is based on the Thiele and Small model with constant parameters (voltage: $0 \mathrm{~V} ; 4 \mathrm{~V}$ )(frequency: $0 \mathrm{~Hz} ; 1000 \mathrm{~Hz})(|Z|:-200 \Omega ;+200 \Omega)$

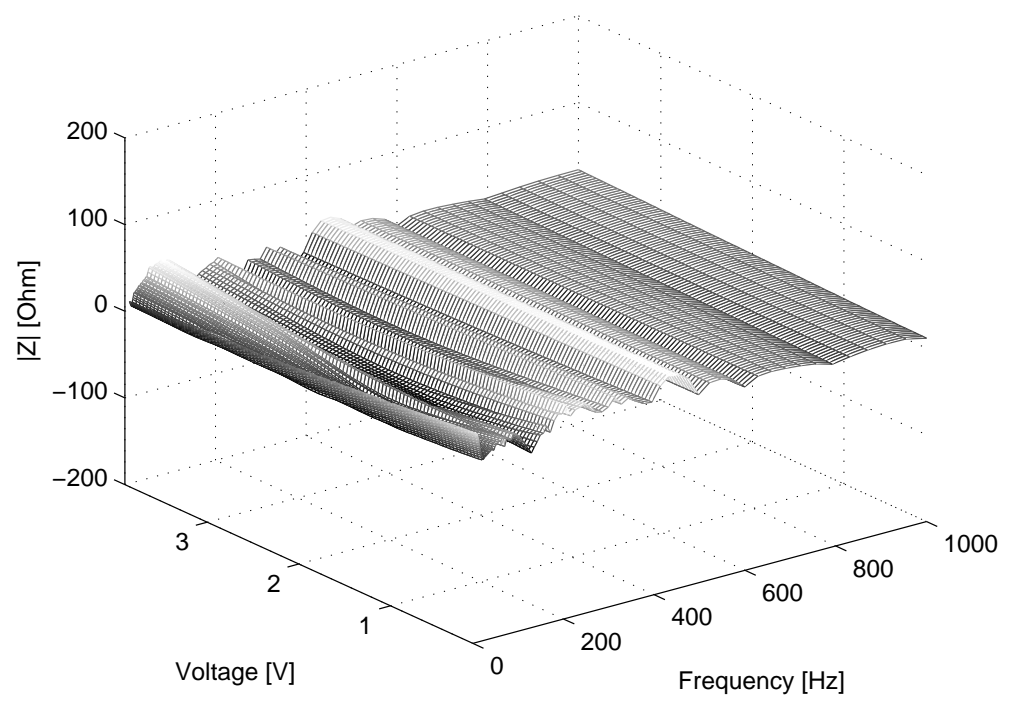

Fig. 6. Three-dimensional representation of the difference between the experimental impedance and the theoretical impedance ; the theoretical impedance is based on the Thiele and Small model with variable parameters (voltage: $0 \mathrm{~V} ; 4 \mathrm{~V}$ )(frequency: $0 \mathrm{~Hz} ; 1000 \mathrm{~Hz})(|Z|:-200 \Omega ;+200 \Omega)$ 


\begin{tabular}{|c|c|c|}
\hline Parameter & Law of variation & sensitivity \\
\hline$R e$ & 490.1 & \\
\hline Le & $0.0023+0.002 u+0.06 u^{2}$ & $15.1 \%$ \\
\hline$B l$ & $13.2-15.1 u+8.09 u^{2}$ & $23 \%$ \\
\hline$R m s$ & $0.25+0.81 u-0.021 u^{2}$ & $4.7 \%$ \\
\hline$M m s$ & $0.00025-0.0014 u+0.0036 u^{2}$ & $18.1 \%$ \\
\hline$k$ & $171.28-50.2 u+1018 u^{2}$ & $2.1 \%$ \\
\hline$R_{\mu}$ & 48.1 & \\
\hline
\end{tabular}

Table 1

Laws of variations of the Thiele and Small parameters

difference allows us to determine the sensitivity of each Thiele and Small parameter. Table 1 presents the laws of variations of Thiele and Small parameters determined with our three-dimensional least mean square method.

It can be noted that the parameter that is the most sensitive to the least mean square algorithm is the force factor $B l$. In addition, we see that the equivalent inductance $L_{e}$ is also sensitive. This implies that the magnetic circuit could be improved. In fact, it is well-known that the iron in magnetic circuits generates nonlinearities because of its saturation and its hysteresis losses. This is the reason why it can be interesting to design ironless magnetic loudspeakers [20]. 
224

$$
\begin{aligned}
u(t)= & \frac{R_{e}}{B l}\left(M_{m s} \frac{d^{2} x(t)}{d t^{2}}+R_{m s} \frac{d x(t)}{d t}+k x(t)\right) \\
& +B l \frac{d x(t)}{d t}+\frac{L_{e}}{B l}\left(M_{m s} \frac{d^{3} x(t)}{d t^{3}}+R_{m s} \frac{d^{2} x(t)}{d t^{2}}+k \frac{d x(t)}{d t}\right)
\end{aligned}
$$

225 The previous equation can also be written in the following form :

$226 \quad u(t)=a \frac{d^{3} x(t)}{d t^{3}}+b \frac{d^{2} x(t)}{d t^{2}}+c \frac{d x(t)}{d t}+d x(t)$ 
with

${ }_{228} \quad a=\frac{M_{m s} L_{e}}{B l}$

${ }_{229} \quad b=\frac{\left(M_{m s} R_{e}+R_{m s} L_{e}\right)}{B l}$

230 $\quad c=\frac{\left(R_{e} R_{m s}+B l^{2}+k L_{e}\right)}{B l}$

${ }_{231} \quad d=\frac{k R_{e}}{B l}$

232

233

234

235

236

237 Thus

238

$$
U=\chi X
$$

239

240

241

242

243

244

245

$$
U=a(j w)^{3} X+b(j w)^{2} X+c(j w) X+d X
$$

where $\chi=\left(A(j w)^{3}+B(j w)^{2}+C(j w)+D\right)$. In the previous section, we studied the fact that the five Small signal parameters depended on input voltage. We deduct that these parameters can also be written as a function of the voice coil position $X$. Therefore, the parameters $a, b, c$ and $d$ in 10 become $a(x), b(x), c(x)$ and $d(x)$ in the nonlinear differential equation of the electrodynamic microphone. It is to be noted that solving this nonlinear differential equation is rather difficult because the denominator is not constant. It can 


$$
\begin{aligned}
x(t)= & a_{1} \cos (w t)+a_{2} \sin (w t)+a_{3} \cos (2 w t)+a_{4} \sin (2 w t) \\
& +a_{5} \cos (3 w t)+a_{6} \sin (3 w t)
\end{aligned}
$$

${ }_{264}$ The parameters $a_{1}, a_{2}, a_{3}, a_{4}, a_{5}$ and $a_{6}$ are determined numerically and are

3.4 Comparison between the theoretical displacement spectrum and the experimental displacement spectrum

A way of obtaining the theoretical displacement spectrum is to solve numerically the nonlinear differential equation of the electrodynamic microphone. This can be done for example in the time-domain by assuming that the electrodynamic microphone generates only harmonics that are multiple of the fundamental harmonic (w, $2 \mathrm{w}, 3 \mathrm{w}$ ). This is a simplifying assumption because input voltage owns in reality many terms so that other typical nonlinear phenomena appear (intermodulations). In short, we assume the solution of the nonlinear differential equation of the electrodynamic microphone to be as the following form:

265 given in Table 2. 


\section{Table 2}

\begin{tabular}{||c|r||}
\hline Coefficient & Value \\
\hline$a_{1}$ & $5.210^{-3}$ \\
\hline$a_{2}$ & $0.8310^{-3}$ \\
\hline$a_{3}$ & $2.4510^{-12}$ \\
\hline$a_{4}$ & $4.1810^{-13}$ \\
\hline$a_{5}$ & $8.8310^{-16}$ \\
\hline$a_{6}$ & $6.1210^{-16}$ \\
\hline
\end{tabular}

Values of the coefficients given in Eq. (18) : these coefficients have been determined with the explicit Runge Kutta method (numerical solving of the nonlinear differential equation of the electrodynamic microphone)

\subsection{Experimental and theoretical displacement spectrums}

This section presents a comparison between the experimental displacement spectrum of the electrodynamic microphone which has been obtained by using a laser Doppler velocimeter and the theoretical displacement spectrum obtained by using the solution given in Eq. (18). The experimental and theoretical values are given in table 3 . Moreover, the results obtained are plotted in Fig. 7. The theoretical displacement spectrum is consistent with the experimental displacement spectrum. Consequently, we deduct that the experimental way of characterizing the electrodynamic microphone with its electrical impedance allows us to precisely estimate the nonlinear variations of the Small signal parameters with the input voltage. 
Table 3

\begin{tabular}{||r|r|r|r||}
\hline & H1 & H2 & H3 \\
\hline $\log \left[x_{\text {exp }}\right]$ & -5.17 & -11.89 & -14.1 \\
\hline $\log \left[x_{\text {theo }}\right]$ & -5.24 & -12.08 & -15.3 \\
\hline
\end{tabular}

Values of the harmonics created by the electrodynamic microphone ; H1 corresponds to the fundamental, $\mathrm{H} 2$ is the harmonic two and $\mathrm{H} 3$ is the harmonic three

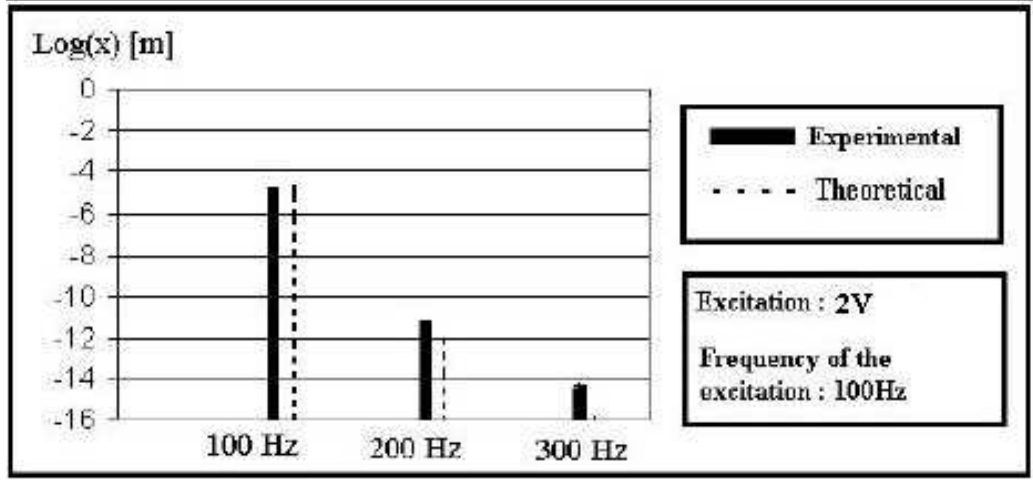

Fig. 7. Experimental and Theoretical spectrums of the electrodynamic microphone

\section{Conclusion}

In this paper, we studied the nonlinear effects of electrodynamic microphones that occur when they are used as acoustical sources. This functioning occurs in reciprocal calibration techniques. An experimental method, based on a very precise electrical impedance measurement allows us to put forward a measurement algorithm which is used to acquire as many points as possible. This measurement algorithm has been put forward in the case of the nonlinear study of electrodynamic loudspeakers. Taking into account the variations of the Small signal parameters with the input voltage allows us to improve significantly the model of the electrodynamic microphone. The variations of the Small signal parameters generate any distortions. These distortions can be predicted by 


\section{References}

[1] M. T. Abuelma'atti, "Improved analysis of the electrically manisfested distortions of condenser microphones," Applied Acoustics, vol. 64, pp. 471-480, May 2003.

[2] M. T. Abuelma'atti, "Harmonic and intermodulation distortion in electret microphones," Applied Acoustics, vol. 34, no. 1, pp. 1-6, 1991.

[3] M. T. Abuelma'atti, "Large signal performance of micromachinened silicon condenser microphones," Applied Acoustics, vol. 68, pp. 1286-1296, October 2007.

[4] M. Niewiarowicz, "Investigations into the transduction properties of dynamic microphone membranes subjected to transients," Applied Acoustics, vol. 22, no. 3, pp. 177-183, 1987.

[5] M. Niewiarowicz, "Determination of active compliance of dome type microphone membranes by using the indicator diagrams method," Journal of Sound and Vibration, vol. 182, no. 4, pp. 589-594, 1995.

[6] S.-M. Hwang, H.-J. Lee, K.-S. Hong, B.-S. Kang, and G.-Y. Hwang, "New develpment of combined permanent-magnet type microspeakers used for cellular phones," IEEE Trans. Magn, vol. 41, no. 5, pp. 2000-2003, 2005.

[7] P. C. P. Chao, C. W. Chiu, and Y. Hsu-Pang, "Magneto-electrodynamical modeling and design of a microspeaker used for mobile phones with 
considerations of diaphragm corrugation and air closures," IEEE Trans. Magn, vol. 43 , no. 6 , pp. $2585-2587,2007$.

[8] P. C. P. Chao and S.-C. Wu, "Optimal design of magnetic zooming mechanism used in cameras of mobile phones via genetic algorithm," IEEE Trans. Magn, vol. 43, no. 6, pp. 2579-2581, 2007.

[9] E. Sadikog, "A laser pistonphone based on self-mixing interferometry for the absolute calibration of measurement microphones," Applied Acoustics, vol. 65, no. 9, pp. 833-840, 2004.

[10] T. Musha and J. I. Taniguchi, "Measurement of sound intensity using a single moving microphone," Applied Acoustics, vol. 66, no. 5, pp. 579-589, 2005.

[11] E. R. Olsen and K. B. Christensen, "Nonlinear modeling of low frequency loudspeakers- a more complete model," in 100th convention, Copenhagen, no. 4205, Audio Eng. Soc., 1996.

[12] J. W. Noris, "Nonlinear dynamical behavior of a moving voice coil," in 105th convention, San Francisco, no. 4785, Audio Eng. Soc., 1998.

[13] A. Dobrucki, "Nontypical effects in an electrodynamic loudspeaker with a nonhomogeneous magnetic field in the air gap and nonlinear suspension," $J$. Audio Eng. Soc., vol. 42, pp. 565-576, 1994.

[14] M. R. Gander, "Dynamic linearity and power compression in moving-coil loudspeaker," J. Audio Eng. Soc., pp. 627-646, September 1986.

[15] M. R. Gander, "Moving-coil loudspeaker topology as an indicator of linear excursion capability," J. Audio Eng. Soc., vol. 29, 1981.

[16] W. M. Leach, "Loudspeaker voice-coil inductance losses : Circuit models, parameter estimation and effect on frequency response," J. Audio Eng. Soc., pp. $442-449,2002$. 
[17] J. R. Wright, "An empirical model for loudspeaker motor impedance," J. Audio Eng. Soc., pp. 749-754, October 1990.

[18] W. Klippel, "Loudspeaker nonlinearities - cause, parameters, symptoms," J. Audio Eng. Soc., vol. 54, pp. 907-939, 2006.

[19] R. Ravaud, G. Lemarquand, V. Lemarquand, and C. Depollier, "Ironless loudspeakers with ferrofluid seals," Archives of Acoustics, vol. 33, no. 4, pp. 310, 2008.

[20] G. Lemarquand, "Ironless loudspeakers," IEEE Trans. Magn., vol. 43, no. 8, pp. 3371-3374, 2007.

[21] R. H. Small, "Closed-box loudspeaker systems, part1: Analysis," J. Audio Eng. Soc., vol. 20, no. 12, pp. 798-808, 1972.

[22] R. Ravaud, G. Lemarquand, and T. Roussel, "Time-varying nonlinear modeling of electrodynamic loudspeakers," Applied Acoustics, vol. 70, no. 3, pp. 450-458, 2009.

[23] A. N. Thiele, "Loudspeakers in vented boxes, part i," J Audio Eng Soc, vol. 19, pp. 382-392, 1971.

[24] A. N. Thiele, "Loudspeakers in vented boxes, part ii," J Audio Eng Soc, vol. 19, pp. $471-483,1971$.

[25] R. H. Small, "Direct-radiator loudspeaker system analysis," J. Audio Eng. Soc., vol. 20, no. 6, pp. 383-395, 1972.

[26] J. Vanderkooy, "A model of loudspeaker driver impedance incorporating eddy currents in the pole structure," J. Audio Eng. Soc., vol. 37, pp. 119-128, March 1989. 